\title{
Combined Spinal Epidural Anesthesia for Total Hip Replacement Surgery in Birendra Army Hospital
}

\author{
KC NB'1, Rai S', Chand ${ }^{2}$, Joshi $A^{2}$, Kunwar BR ${ }^{1}$
}

${ }^{1}$ Department of anesthesiology, Shree Birendra Hospital, ${ }^{2}$ Department of Orthopedics, Shree Birendra Hospital.

\begin{abstract}
Introduction: Total Hip Replacement surgery is one of the most commonly performed surgeries worldwide. Epidural anaesthesia have shown decrease incidence of DVT in these patient. Hence, combined spinal epidural spinal anesthesia is now a preferred technique over spinal anesthesia alone. We have been practicing combined spinal epidural anesthesia routienely in total joint replacement, but have not analyzed the result. The aim of this study was to analyse various aspect of combined spinal epidura anesthesia.

Methods: thirteen cases of ASA I and II who underwent Total Hip Arthroplasty under combined spinal epidural anesthesia were analysed. First epidural was given in space L2-3/L3-4 and patency was confirmed with test dose with InjXylocaine $2 \%$ with Adrenaline $3 \mathrm{ml}$, followed by Spinal anesthesia one space below with Bupivacaine $0.5 \% 3 \mathrm{ml}$.

Results: Intra operative Mean Blood Pressure had dropped up to $55 \mathrm{~mm}$ of $\mathrm{Hg}$. To maintain Blood pressure, Intravenous Fluid was given in average is $2423.077 \mathrm{ml}$ and Vasopressure drug(Mephenteramine Maleate) was given in average of $14.769 \mathrm{mg}$. Dura was accidentally puncture in one patient during epidural insertion and two epidural failed to provide post operative analgesia. Post operative rehabilitation was easy, one one patient developed DVT after 4 weeks of surgery.

Conclusion: Combined epidural analgesia effectively manages postoperative pain, allows early ambulation and reduces the risk of deep vein thrombosis and thromboembolism, Although significant drop of Blood pressure was noted in all cases.
\end{abstract}

Key words: Combined Spinal Epidural, CSE, Epidural catheter, Spinal needle, Total Hip Replacement, THR

\section{Introduction}

Total Hip Replacement (THR) is one of the most commonly performed orthopedic procedure worldwide. Although THR is common in Nepal, it has been introduced in our institution recently.Initially we started with general anesthesia, as we were not certain about the time required for surgery because of initial days in the joint replacement surgery. Once we and the surgeons were confident and oriented to the methods then we started providing spinal anesthesia for these patients. Later when THR became frequent surgery in our institution then we started to modify and improve our anesthetic approach and decided to provide Combined Spinal Epidural (CSE). CSE anesthesia has advantage of early onset and post operative analgesia to facilitate rehabilitation. It has also shown to reduce the incident of DVT which is the most feared complication after THR.Although at first sight the CSE technique appears to be more complicated than either epidural or spinal block, intrathecal drug administration and placement of the epidural catheter are both facilitated by the various modifications of the combined spinal-epidural technique ${ }^{1}$. Broadly CSE technique is classified into two types: single segment technique (SST) and double segment techniques (DST). If both the epidural and the spinal punctures are performed in the same interspace

\section{Address for Correspondence:}

Name: Dr. Nagendra Bahadur KC

E-mail:drnkcbinita@gmail.com

Ph. No.: 9851044030 
it is called SST or single interspace CSE technique and the others are named DST or double interspace CSE technique. These can be further classified according to the type of needle used that is Single Lumen Epidural Needles (Needle-through-Needle technique) and Double Lumen Needles(Needle-besides-Needle technique $)^{2}$. The earlier methods to identify the epidural space were the feel and hear method of Pages, positive plunger pressure by Dogliotti, "hanging drop" method by Gutierrez and the balloon deflation technique by Macintosh and Oxford ${ }^{3}$. Most of these techniques were based on the concept of "negative" pressure in the extradural space. We also used the technique of loss of resistance with pushing air during advancement towards the epidural space, which is easy technique to identify epidural space. However a new technique "membrane in syringe" technique is a modification of the loss of resistance technique for identifying the epidural space ${ }^{4}$. Whatever the technique or method, the CSE anesthesia have proved to be beneficial in various aspect. No study has been performed in our institution to evaluate CSE anesthesia. So, this retrospective analytical study was performed to evaluate the efficacy, advantages and complications of Combined Spinal Epidural Anesthesia for Total Hip replacement Surgery.

\section{Methods}

This was a retrospective, hospital based, descriptive study done at Shree Birendra Hospital, Chhauni Kathmandu, over a period of two years from 2008 to 2010. During this period 18 patient underwent THR. Five cases receivedeither general anesthesia, spinal or epidural anesthesia only. So, they were excluded from this study which left us 13 patients for final analysis (Table-1).

We performed the Double lumen needles technique where an epidural needle and spinal needle are introduced through separate lumen in separate space.

All patients underwent through Pre Anesthetic checkup generally one week before the surgery and look for any associated co-morbid medical problem as most of the patients are from elderly group. They were advised to arrange 4 unit of whole cross matched blood. Patient and patient party were counseled and explained in detail about the nature and consequences of surgery. Minimum Hemoglobin level was set $10 \mathrm{Gm} \%$. Day before surgery Patient is again re-evaluated and tab. Diazepam $5 \mathrm{mg} \mathrm{HS}$ was given. Patient is categorized as ASA class.

In day of surgery in Operation Theater I/V line is opened with either $16 \mathrm{~g}$ or $18 \mathrm{~g}$ cannula and routine monitors are put on. Initially Ringer lactate $500 \mathrm{ml}$ fluid is preloaded and Initial Base line Blood pressure and Pulse was recorded. Then in sitting position, Epidural space is identified with air filled syringe with loss of resistant technique in L2-3 or L3-4 space and catheter is kept $5-7 \mathrm{~cm}$ inside epidural space. Then $3 \mathrm{ml}$ of test dose of Injection Xylocaine $2 \%$ with adrenaline is given to confirm the right placement of catheter. Then Sub arachnoid block is done one space below of epidural catheter placement that is either L3-4 or L4-5 space with $25 \mathrm{~g}$ Quincke spinal needle and Injection Bupivacaine $0.5 \%$ (Heavy) $3 \mathrm{ml}$ was given. Then patient was kept in supine position till loss of sensation and motor power of lower limb is abolished. When surgical anesthesia was reached, Foly'sCatheterization was done. Patient is kept in lateral position and surgeon is asked to start preparation and surgical procedure. Blood pressure and heart rate was recorded in every 5 minutes with close continuous ECG and SpO2 monitoring. If Blood pressure goes below $90 / 60 \mathrm{~mm}$ of $\mathrm{Hg}$ or $30 \%$ below of base line, InjMepheteramine maleate $6 \mathrm{mg}$ in increament doses given along with fast fluid infusion to keep up Blood Pressure above $90 / 60 \mathrm{~mm}$ of $\mathrm{Hg}$ and total received drug is recorded. All Patient also initially received Colloid (Gelofusine) 500ml. Any other complications during procedure were also recorded and complications were treated accordingly. Total duration of operative procedure and need of top op epidural anesthesia with injection Bupivacaine $0.5 \%$ is also noted. Intraoperative loss of Blood is also noted and Intra operative transfusion of blood is also noted. At the end of surgery total infused I/V Crystalloid fluid and Urine output is also noted.

Table 1: Different cases for THR (n-13)

\begin{tabular}{|c|l|c|c|c|}
\hline S. No & Hip Pathology & Rt. Side & Lt. Side & Total Numbers \\
\hline 1. & Osteoarthritis(OA) & 3 & 6 & 9 \\
\hline 2. & Aseptic Loosening Femaoral head component & 1 & 0 & 1 \\
\hline 3. & Avascular Necrosis(AVN) & 1 & 1 & 2 \\
\hline 4. & Secondary Osteomylitis & 1 & 0 & 1 \\
\hline & & $\mathbf{6}$ & $\mathbf{7}$ & $\mathbf{1 3}$ \\
\hline
\end{tabular}


After completion of surgery, patient is transferred to post operative ward and kept in monitor atleast for 24 hours. For post operative pain management, epidural analgesia is advised as injection bupivacaine $0.125 \%$ $10-12 \mathrm{ml} \mathrm{4-6}$ hourly. For rescue analgesia Injection pethidine 50mg and Injection Phenargan 25mg 6-8 hourly advised. For deep vein thrombosis prophylaxis, InjectionEnoxaperin $\mathrm{HCl} 40 \mathrm{mg} \mathrm{S} / \mathrm{C}$ OD is given. Patients were comfortable due to epidural analgesia and Post operative epidural analgesia is continued for 72 hours. All patients are advised to walk early on $3^{\text {rd }}$ post-operative day which was possible with the help of

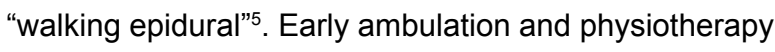
is started.

\section{Results}

In our study, average age was 55.53 years ranging from 22 to 80 years and Male were more than Female patient at the ratio of 8:5. Average weight of the patients in this study population was $59.69 \mathrm{Kg}$. Average Hemoglobin levelwas $11.89 \mathrm{Gm} \%$. In this study average duration of surgery was 188.84 minute. Intra op Mean Blood Pressure had dropped up to 55 $\mathrm{mm}$ of $\mathrm{Hg}$ and average mean Arterial Blood pressure was $63.15 \mathrm{~mm}$ of $\mathrm{Hg}$ and to maintain blood pressure, intravenous fluid was given in average is $2423.077 \mathrm{ml}$ and vasopressure drug (mephenteramine maleate) was given at the average of $14.769 \mathrm{mg}$. Urine output was well maintained and average urine output was $530.769 \mathrm{ml}$. Averageintroperative blood loss was $984.615 \mathrm{ml}$ ranging from $500-1500 \mathrm{ml}$. All the patients received intraoperative blood transfusion.

We found dura puncture and leak of cerebrospinal fluid in one patient $(7.69 \%)$ during epidural procedure and subarachnoid block was given in this case.
Complete failure of post op analgesia was seen in two patients (15.38\%), opoid analgesia was given to them. One patient had developed DVT after 4 weeks of surgery(Table 3).

Table 3: Complications

\begin{tabular}{|l|l|}
\hline Dura puncture, CSF leak & $1(7.69 \%)$ \\
\hline Failure of post op analgesia & $2(15.38 \%)$ \\
\hline DVT & $1(7.69 \%)$ \\
\hline
\end{tabular}

\section{Discussion}

The Combined spinal epidural technique (CSE), a comparatively new technique, includes an initial subarachnoid injection followed by epidural catheter placement and administration of epidural medications. This allows for almost immediate relief of pain or induction of regional anesthesia by the rapid onset of spinal drugs, and subsequent administration of medications for prolonged anesthesia. In addition, postoperative analgesia via the epidural catheter can be delivered for extended periods. The introduction of CSE anesthesia offers benefits of both spinal and epidural anesthesia.

Although the CSE technique has become increasingly popular over the past two decades, it is a more complex technique that requires comprehensive understanding of epidural and spinal physiology and pharmacology and need experienced anesthesiologist. There is a need a concern over the frequency of CSE related complications, controversy over the technique and the failure rates with CSE technique $e^{6,7,8}$.

McDonald $S$ et al described in their article that there is evidence to support the use of pre operative education to improve post operative outcomes in patients undergoing hip or knee replacement surgery, especially

Table 2: Demographic data of the study Population $(n=13)$

\begin{tabular}{|l|l|}
\hline Age (Years) & 55.53846 (range 22-80) \\
\hline Sex (M/F) & $8(61.83 \%) / 5(38.46 \%)$ \\
\hline Weight (Kilogram) & 59.69231 (range 48-73) \\
\hline Pre op Hemoglobin (Gm\%) & 11.89231 (range 9.6-13.5) \\
\hline Duration of Surgery & 188.8462 (range 145-230) \\
\hline $\begin{array}{l}\text { Intra op mean Blood pressure during resection period } \\
\text { (mm of Hg) }\end{array}$ & 63.15385 (range 55-76) \\
\hline Total used Injection Mephenteremine Maleate (in mg.) & 14.76923 (range 0-24) \\
\hline Total infused Crystalloid Fluid (in ml) & 2423.077 (range 2000-3000) \\
\hline Total urine output (in ml) & 530.7692 (range 350-700) \\
\hline Intra op Blood loss (ml ) & 984.6154 (range 500-1500) \\
\hline Blood transfusion done (no of Pt.) & $13(100 \%)$ \\
\hline
\end{tabular}


with respect to pain, functioning and length of hospital stay. There is evidence that preoperative education has a modest beneficial effect on preoperative anxiety. ${ }^{9}$ In our cases also, Preoperative check up and detailed explanation of CSE procedure was explained, which made patient to cooperate during CSE procedure and post op epidural analgesia.

CSE often produces a more extensive block than expected. The possible mechanisms have been postulated are leakage of epidural local anesthetic through the dural hole into the subarachnoid space and compression of subarachnoid space by the presence of epidural catheter and by the volume of local anesthetic, resulting in a"squeezing" of CSF and more extensive spread of local anesthetic drugs ${ }^{10,11}$. This may be a cause of extensive sensory and motor block resulting hypotension which is seen in our all cases and need to rescue with vasopressorand fluid load. It was recommended to use less volume of Local Anesthetic drug for sub arachnoid block to avoid the complication of extensive block.Although T Ezri et al in their study found similar incidence of hypotension in spinal alone or CSE cases ${ }^{12}$.

Adequate pain relief is essential in the postoperative period to enable early ambulation and initiation of physiotherapy after THR surgery. Lumbar epidural analgesia is a common modality for pain relief following major lower abdominal surgical procedures including THR. We also continued epidural analgesia for the post op pain control with plain bupivacaine $0.125 \%$ alone and found to have been adequate. However a systemic review concluded that the benefits may be limited to the early (four to six hours) postoperative period. An epidural infusion of local anesthetic or local anesthetic-narcotic mixture may be better than epidural narcotic alone. The magnitude of pain relief must be weighed against the frequency of adverse events. The current evidence is insufficient to draw conclusions on the frequency of rare complications from epidural analgesia, postoperative morbidity or mortality, functional outcomes, or length of hospital stay ${ }^{13}$.

A transient period of hypercoagulability can occur during and after major orthopaedic surgery thus the risk of secondary haematologic complications such as deep vein thrombosis or pulmonary embolism increases significantly.Both pharmacologic and nonpharmacologic options are available for prevention of venous thromboembolic events (VTEs) ${ }^{14}$. The combined use of both confers a good result and in our cases we had used Low molecular weight Heparin and we had only one case of DVT.

Blood loss during surgery was significant in our cases and need of Blood transfusion required in all cases. This was supported by one study published by Wakamatsu $\mathrm{M}$ et al, that the rate of operative blood loss was significantly higher in the CSE anesthesia than in the general anesthesia.In their study,a significant increase in total volume of perioperative blood loss was also observed in the group with CSE anesthesia (1520 $+/-90 \mathrm{ml}$ ) compared with the general anesthesia group $(1279+/-58 \mathrm{ml})^{15}$. Contrary of this, in another study, Willium $\mathrm{J}$ and colleague reported that neuraxial block anesthesia is associated with a decrease incidence of blood transfusion as compared to THR under general anesthesia ${ }^{16}$.

CSE technique results in a rapid onset of surgical anesthesia, often 15-20 min faster than with epidural anesthesia. The epidural catheter insertion after the spinal component allows supplementing insufficient subarachnoid anesthesia as well as extending anesthesia or analgesia as necessary. CSE has been reported to decrease the failure rate and incidence of adverse events of neuraxial analgesia. Thus CSE is an ideal choice for lower limb major orthopedic surgery.

\section{Conclusion}

CSE is an ideal choice taking advantages of both, surgical anesthesia during Intra op period and to manage postoperative pain which allows early ambulation and reduce mortality in THR surgery. Epidural analgesia effectively manages postoperative pain, allows early ambulation and reduces mortality in THR replacement surgery by decreasing deep vein thrombosis and thromboembolism. Bleeding during operation is significant and need blood transfusion in all cases. Drop of Blood pressure was also noted and rescue medication was needed in all cases. No other significant complication is noted.

\section{References}

1. Rawal N, Holmstrom B, Crowhurst JA et al. The combined spinal-epidural technique. AnesthesiolClin North America. 2000; 18(2): 26795.

2. Cook TM. 210 Combined spinal-epidurals for anaesthesia using a separate needle technique. Eur J Anaesthesiol 2004; 21(9): 679-83. 
3. Miller's anesthesia 6th ed Elsevier / Churchil living stone 2004; 27.

4. Lin BC, Chen KB, Chang CS et al. A 'membrane in syringe' technique that allows identification of the epidural space with saline while avoids injection of air into the epidural space. ActaAnaesthesiol Sin 2002; 40(2): 55-60.

5. Schneider MC. Walkingepidurals: mobilisation during neuraxiallabour analgesia. AnesthesiollntensivemedNotfallmedSchmerzther 2007 May;42(5):352-9.

6. Norris MC. Are combined spinal epidural catheters reliable? Int J ObstechAneaesth 2000;9:3-6.

7. Reynolds F. Damage to the conusmedullaris following spinal anesthesia. Anesthesia 2001;56:238-247.

8. Cook TM. Combined spinal-epidural technique. Anesthesia 2000;55:42-64

9. McDonald S, Hetrick S, Green S. Pre operative education for Hip or Knee replacement. Cochrane database Syst Rev, 2004;(1):CD003526.

10. LewE, YeoSW, ThomasE. Combined spinal-epidural anesthesia using epidural volume extension leads to faster motor recovery after elective cesarean delivery: A prospective, randomized, double-blind study. AnesthAnalg 2004; 98(3):810-44.
11. Steinstra R, Dahan A, Alhadi ZRB, van Kleef JW, Burm AGL. Mechanism of action of an epidural top-up in combined spinal-epidural anaesthesia. AnesthAnalg 1996; 83: 382-86.

12. T. Ezri, I. Zahalka, D. Zabeeda etal. Similarincidence of hypotension with combined spinal epidural or epidural alone alone for knee arthroplasty. Can J Anesth, Feb 1, 2006;53(2): 139-145.

13. Choi PT, Bhandari M, Scott J, Douketis J. Epidural analgesia for pain relief following hip or knee replacement: Cochrane Database Syst Rev, 2003;(3):CD003071.

14. Andrew $P$ Kurmis. Review Article: Thromboprophylaxis after total hip replacement. Journal of orthopedic surgery 2010; 18(1): 92-7.

15. Wakamatsu M, Ono K, Katoh $\mathrm{H}$ et al. Effect of combined spinal and epidural anesthesia on blood loss during total hip replacement. Masui, 1993 Jan;42(1):56-9.

16. Willium J. Mauermann, MD., Ashley M. Shilling, MD., ZhiyiZuo, MD,Ph.D. A Comparision of Neuraxial Verses General Anesthesia for elective Total hip replacement : A Meta-Analysis. Anesthesiology 2005;103:A1158. 